Bull. Mater. Sci., Vol. 36, No. 1, February 2013, pp. 163-170. (C) Indian Academy of Sciences.

\title{
A soluble-lead redox flow battery with corrugated graphite sheet and reticulated vitreous carbon as positive and negative current collectors
}

\author{
A BANERJEE, D SAHA, T N GURU ROW and A K SHUKLA* \\ Solid State and Structural Chemistry Unit, Indian Institute of Science, Bangalore 560 012, India
}

MS received 3 August 2012; revised 23 August 2012

\begin{abstract}
A soluble-lead redox flow battery with corrugated-graphite sheet and reticulated-vitreous carbon as positive and negative current collectors is assembled and performance tested. In the cell, electrolyte comprising of $1.5 \mathrm{M}$ lead (II) methanesulfonate and $0.9 \mathrm{M}$ methanesulfonic acid with sodium salt of lignosulfonic acid as additive is circulated through the reaction chamber at a flow rate of $50 \mathrm{ml} \mathrm{min}-1$. During the charge cycle, pure lead $(\mathrm{Pb})$ and lead dioxide $\left(\mathrm{PbO}_{2}\right)$ from the soluble lead (II) species are electrodeposited onto the surface of the negative and positive current collectors, respectively. Both the electrodeposited materials are characterized by XRD, XPS and SEM. Phase purity of synthesized lead (II) methanesulfonate is unequivocally established by single crystal X-ray diffraction followed by profile refinements using high resolution powder data. During the discharge cycle, electrodeposited $\mathrm{Pb}$ and $\mathrm{PbO}_{2}$ are dissolved back into the electrolyte. Since lead ions are produced during oxidation and reduction at the negative and positive plates, respectively there is no risk of crossover during discharge cycle, preventing the possibility of lowering the overall efficiency of the cell. As the cell employs a common electrolyte, the need of employing a membrane is averted. It has been possible to achieve a capacity value of $114 \mathrm{mAh} \mathrm{g}^{-1}$ at a load current-density of $20 \mathrm{~mA} \mathrm{~cm}{ }^{-2}$ with the cell at a faradaic efficiency of $95 \%$. The cell is tested for 200 cycles with little loss in its capacity and efficiency.
\end{abstract}

Keywords. Soluble-lead redox flow battery; corrugated graphite sheet; reticulated vitreous carbon; battery cycle-life; sodium salt of lignosulfonic acid.

\section{Introduction}

Intermittent and unpredictable nature of renewable energy from sun and wind demands them to be coupled with an energy storage system. This energy storage requirement has stimulated a renaissance in redox-flow batteries wherein energy and power are decoupled and energy more than weight and volume happens to be the key metric (Adam and Meyers 2011). Among the various redox-flow batteries, soluble-lead redox flow battery is especially attractive as it employs single electrolyte, has no separating membrane and consequently is relatively cost-effective. Besides, lead form of the cell is nearly-fully recyclable. In the literature (Hazza et al 2004, 2005; Pletcher and Wills 2004, 2005; Peng et al 2007; Pletcher et al 2008; Wills et al 2010), soluble-lead redox flow batteries have been studied extensively but a study on the soluble-lead redox flow battery employing corrugated graphite sheet and reticulated vitreous carbon as positive and negative current collectors is lacking.

In this study, we report a soluble-lead redox flow battery with corrugated-graphite sheet and reticulated-vitreous carbon as positive and negative current collectors. During the study, electrodeposited active materials have been characterized by XRD, XPS and SEM images. The flow cells are electrochemically performance tested at varying load

\footnotetext{
*Author for correspondence (akshukla2006@gmail.com)
}

current-densities. After the cycle life tests, lead (II) salt could be nearly fully recovered from the cell, indicating its environmental compatibility.

\section{Experimental}

\subsection{Experimental set up for soluble-lead redox flow battery}

A soluble-lead redox flow battery is shown schematically in figure 1 . The battery comprises of a reaction chamber (cell) and an electrolyte reservoir. The cell consists of a pair of dense graphite sheets current collectors (dimension: $3.5 \mathrm{~cm} \times$ $3.5 \mathrm{~cm} \times 1 \mathrm{~mm})$. The inter-electrode distance was $0.5 \mathrm{~cm}$ and electrolyte volume in the cell was $170 \mathrm{ml}$. The electrolyte was circulated between the reservoir and the cell through a d.c. pump (Model: NF 5 RPDC - L/ Voltage: 6 V / Current: $0.067 \mathrm{~A}$ / Power: $0.4 \mathrm{~W}$ ) at a flow rate of $50 \mathrm{ml} \mathrm{min}^{-1}$. During the operation of the battery the mass-transport limitation was minimized through adequate flow of the electrolyte.

\subsection{Selection of positive and negative current collectors for soluble-lead redox flow battery}

Corrugated-graphite sheets were employed as positive plate current collectors in order to increase the electrode area while flat graphite sheets covered with reticulated vitreous 
carbon (RVC) were employed as negative plate current collectors. RVCs provide high surface area and good mechanical support to the active materials. We used three types of RVCs with varying porosities, viz. 20,30, $45 \mathrm{ppi}$, for optimization. The surface morphology of bare graphite and RVCs are provided under supplementary information in figure S1. The sustainability of the active materials onto the surface of current collectors depends on the surface roughness and particle size of active materials. The optimization study has been conducted on corrugated graphite surface and different RVCs of 20, 30, 45 ppi to obtain the best combination of positive and negative current collectors. An appreciable amount of fine lead dioxide particles were deposited inside the pores of RVC. As a result that amount of active material was entrapped within the pores. Accordingly, the utilization of positive active material during discharge was reduced. By contrast, coarse lead particles were mainly deposited onto

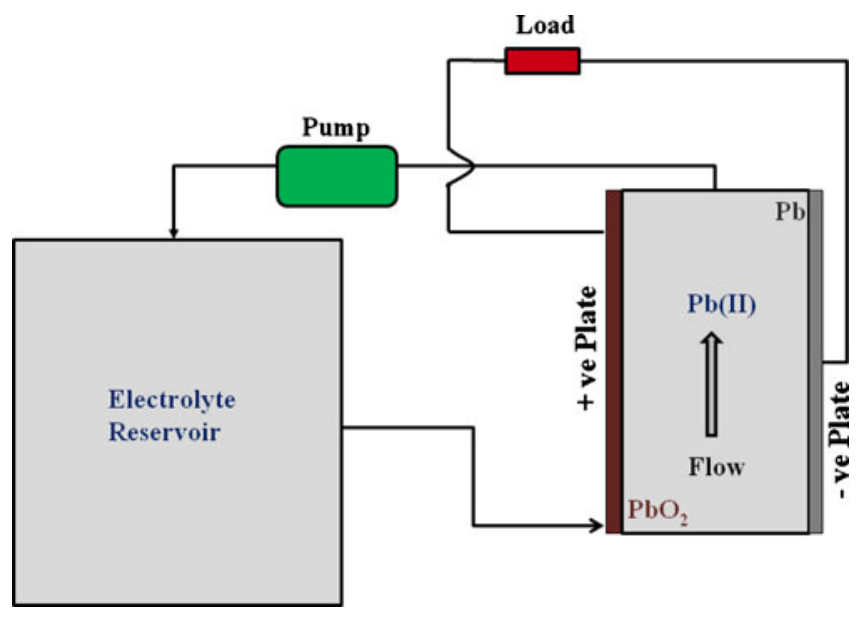

Figure 1. Schematic diagram for a soluble-lead redox flow battery. the mouth of the pores of RVC and hence utilization was not a problem during the discharge at the negative plate. In the light of the foregoing, RVC is not suitable as current collector for positive plates. Instead, corrugated graphite sheets are found to be appropriate current collectors for positive plate. The performance data on different combinations are summarized in tables 1 and 2 . The cell discharge data for each combination are included under supplementary information in figures $\mathrm{S} 2$ and $\mathrm{S} 3$. The optimized configuration was found to be the corrugated graphite as positive plate and 30 ppi RVC as negative plate as shown in figure 2 .

\subsection{Preparation of electrolyte solution}

Aqueous solution of lead (II) methanesulfonate salt with methanesulfonic acid (1.5 M: 0.9 M, respectively) was used as electrolyte (Hazza et al 2004). Lead (II) methanesulfonate salt was synthesized from litharge $(\mathrm{PbO})$ and methanesulfonic acid in 1:2 molar ratios, respectively. Finely ground litharge powder was gradually added to the aqueous solution of methanesulfonic acid with vigorous stirring. The resulting solution was mechanically stirred for $2 \mathrm{~h}$. Subsequently, excess water was evaporated by heating to obtain white crystalline salt. Lead (II) methanesulfonate salt can be recrystallized from already used electrolyte solution by evaporation of excess water. In this manner, disposal problem of lead containing solution could be averted.

\subsection{Crystal growth and X-ray diffraction analysis of lead (II) methanesulfonate salt}

The purity of lead (II) methanesulfonate was confirmed by powder X-ray diffraction analysis. Powder XRD data were collected using a Philips X-pert Pro diffractometer with $\mathrm{Cu} \mathrm{K} \alpha$ radiation over a $2 \theta$ range of $5-50^{\circ}$, with a step width

Table 1. Optimization of corrugated graphite and 30 ppi RVC for positive and negative current collectors.

\begin{tabular}{lccc}
\hline Positive plate & Negative plate & Capacity $\left(\mathrm{Ah} \mathrm{g}^{-1}\right)$ & Efficiency (\%) \\
\hline Corrugated graphite & Corrugated graphite & $0 \cdot 075$ & 57 \\
Corrugated graphite & RVC (30ppi) & $0 \cdot 114$ & 95 \\
RVC (30ppi) & RVC (30ppi) & $0 \cdot 094$ & 79 \\
RVC (30ppi) & Corrugated graphite & 0.085 & 73 \\
\hline
\end{tabular}

Data at $20 \mathrm{~mA} \mathrm{~cm}^{-2}$ discharge after $1 \mathrm{~h}$ charge at same current.

Table 2. Optimization of RVCs for negative current collectors.

\begin{tabular}{lccc}
\hline Positive plate & Negative plate & Capacity $\left(\mathrm{Ah} \mathrm{g}^{-1}\right)$ & Efficiency (\%) \\
\hline Corrugated graphite & RVC (20ppi) & $0 \cdot 107$ & 88 \\
Corrugated graphite & RVC (30ppi) & $0 \cdot 114$ & 95 \\
Corrugated graphite & RVC (45ppi) & 0.108 & 89 \\
\hline
\end{tabular}

Data at $20 \mathrm{~mA} \mathrm{~cm}^{-2}$ discharge after $1 \mathrm{~h}$ charge at same current. 


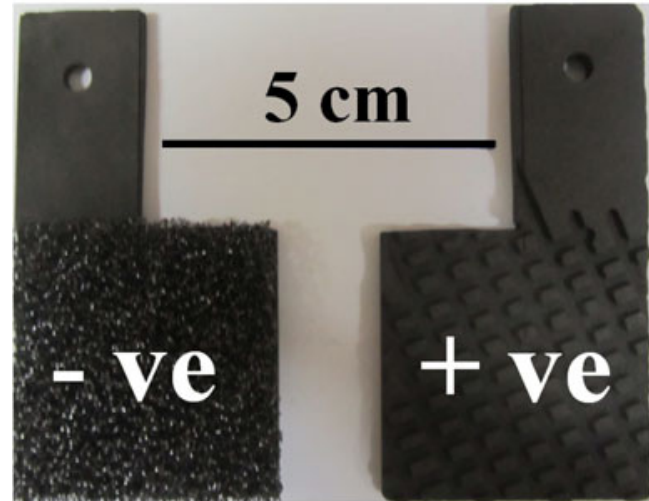

Figure 2. Photographic images for positive and negative current collectors.

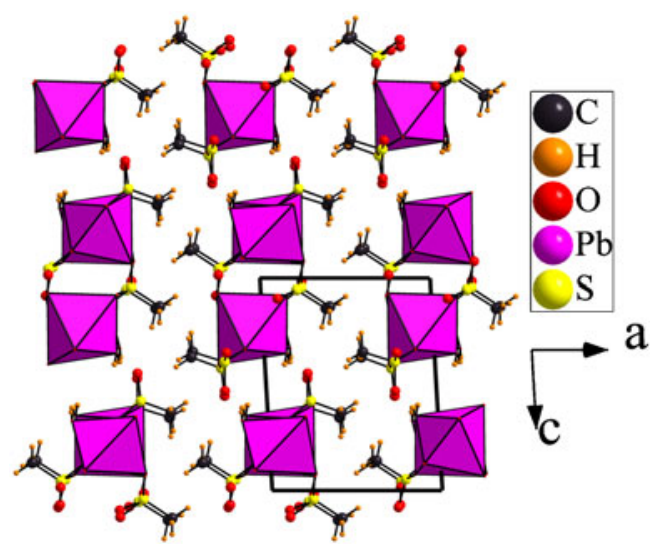

Figure 3. Packing diagram of lead (II) methanesulfonate. of $0 \cdot 0167^{\circ}$. Le Bail profile fitting was carried out using XRD data by the JANA2000 (Petricek et al 2007) suite of programs. The background was estimated by a Legendre polynomial function consisting of 15 coefficients, and the peak shapes were described by a pseudo-Voigt function, varying five profile coefficients. A scale factor, a zero error factor, and a shape function were refined.

Single crystals of lead (II) methanesulfonate were grown by slow evaporation method from water solution. Good quality crystals were chosen under polarizing microscope for single crystal X-ray diffraction studies. Single crystal X-ray diffraction data were collected on Xcalibur ${ }^{\mathrm{TM}}$ Mova E diffractometer with four circle kappa goniometer and Eos CCD detector in CrysAlis CCD, Agilent technologies employing a graphite-monochromatized Mo $\mathrm{K} \alpha(\lambda=$ $0.7107 \AA$ ) radiation at $298(2) \mathrm{K}$ with $\mathrm{X}$-ray generator, $50 \mathrm{kV}$ and $0.8 \mathrm{~mA}$. The cell refinement and data reduction were accomplished using CrysAlis RED (Agilent technologies 2012). The diffraction intensities were corrected for Lorentz and polarization effects. The data were reduced using CrysAlis RED (special programs available with the diffractometer), the shape was determined with a video microscope attached to the diffractometer, and an analytical absorption correction (after Clark and Reid) was applied. The structures were solved by direct method using SHELXL97 (Sheldrick 2008) using the program suite WINGX (version 1.70·01) (Farrugia 1999). The packing diagrams were generated using package Diamond, Version 2·1c (Brandenburg 1999).

All the electrochemical tests were conducted on an Autolab Potentiostat/Galvanostat-Model 30. Single electrode potentials were recorded during charge and discharge against MMS (0.665 V vs SHE) electrode using a Keithley 2100 DMM Digital Multimeter interfaced with a computer.

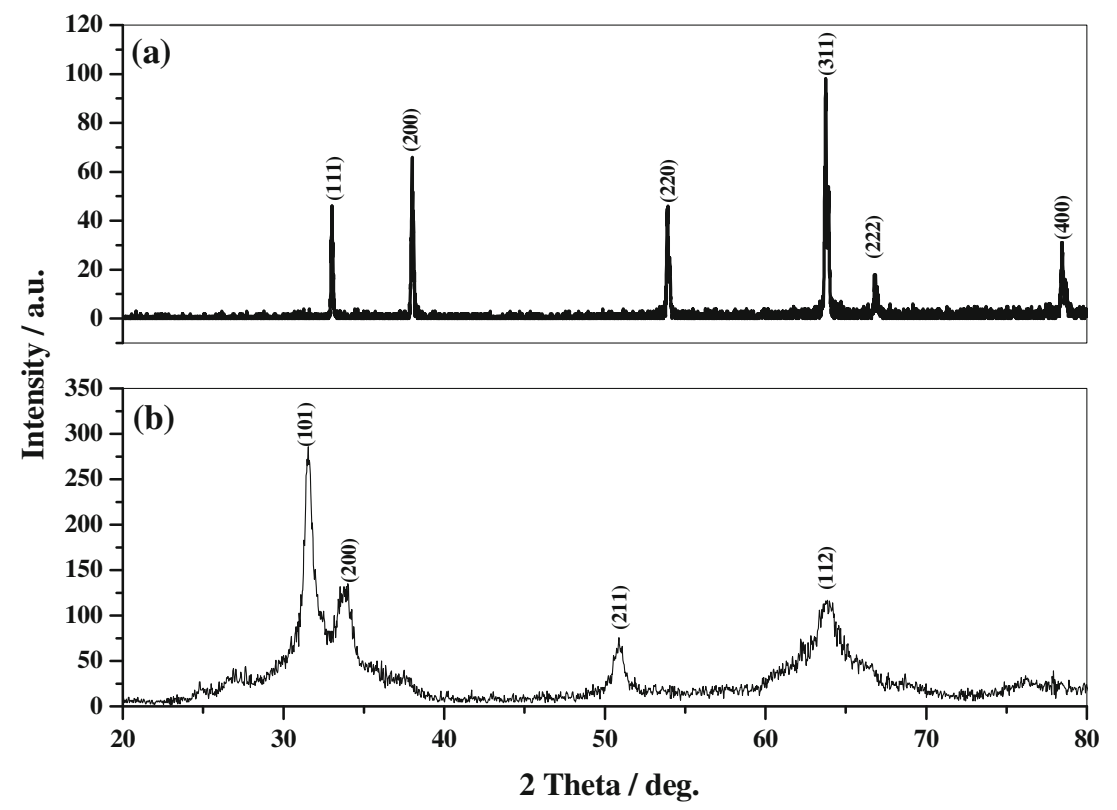

Figure 4. $\mathrm{X}$-ray diffraction patterns for (a) negative active material $(\mathrm{Pb})$ and (b) positive active material $\left(\mathrm{PbO}_{2}\right)$. 
X-ray diffraction patterns were recorded on a Philips X'pertPro X-ray Diffractometer equipped with X'cellerator detector at a scan speed $(\% / s)$, step size $\left({ }^{\circ}\right)$ and time per step (s) values of $0 \cdot 053,0.0167$ and 0.30 , respectively. X-ray photoelectron spectra (XPS) for the formed electrodes were obtained on a MultiLab 2000 Photoelectron Spectrometer from Thermoscientific, UK. SEM images were obtained on JEOL JSM-5600LV Scanning Electron Microscope for the current collectors only and ESEM-Quanta instrument was used for obtaining the morphology of deposited active materials. Sirion-SEM instrument was used for obtaining high resolution image of electrodeposited lead dioxide.

All the experiments were performed at room temperature $\left(\sim 28^{\circ} \mathrm{C}\right)$. All the chemicals were purchased from Sigma-Aldrich chemicals and were used without any further purification.

\section{Results and discussion}

In a soluble-lead redox flow cell, the electrolyte containing lead (II) methanesulfonate salt flows between the electrodes with concomitant formation and deposition of lead $(\mathrm{Pb})$ and lead dioxide $\left(\mathrm{PbO}_{2}\right)$ onto the electrode surfaces from lead (II) species by reduction and oxidation during the charging process, respectively. On cell discharge, deposited lead and lead dioxide are dissolved as soluble lead (II) species in the electrolyte. The electrode reactions at the negative and positive plates during cell charge/discharge are depicted below.

At negative plate:

$$
\begin{aligned}
& \mathrm{Pb}^{2+}+\underset{\text { discharge }}{2 e^{-}} \stackrel{\text { charge }}{\rightleftharpoons} \mathrm{Pb} \\
& E_{\text {negative plate }}^{0}=-0.13 \mathrm{~V} \text { vs SHE. }
\end{aligned}
$$

At positive plate:

$$
\begin{aligned}
& \mathrm{Pb}^{2+}+2 \mathrm{H}_{2} \mathrm{O}-\underset{\text { discharge }}{2 e^{-}} \stackrel{\text { charge }}{\rightleftharpoons} \mathrm{PbO}_{2}+4 \mathrm{H}^{+} \\
& E_{\text {positive plate }}^{0}=1.49 \mathrm{~V} \text { vs SHE. }
\end{aligned}
$$

The overall cell reaction is given as:

$$
\begin{aligned}
& 2 \mathrm{~Pb}^{2+}+\underset{\text { discharge }}{2 \mathrm{\textrm {H } _ { 2 } \mathrm { O }} \rightleftharpoons \mathrm{Pb}}+\mathrm{PbO}_{2}+4 \mathrm{H}^{+} \\
& E_{\text {cell }}^{0}=1.62 \mathrm{~V} \text { vs SHE. }
\end{aligned}
$$

The operational details with relevant data are described in the following sub-sections.

\subsection{Single crystal structure and X-ray powder diffraction of lead (II) methanesulfonate salt}

Single crystal X-ray diffraction studies were carried out to unequivocally establish the structure of lead (II) methanesulfonate. It reveals that the compound crystallizes in a triclinic system with space group $P-1$ and cell parameters $a=8 \cdot 8594(9) \AA, b=9 \cdot 8298(11) \AA, c=10 \cdot 6332(13) \AA, \alpha=$ $88.001(9)^{\circ}, \beta=86.234(9)^{\circ}, \gamma=71.598(9)^{\circ}$ (see supplementary information table $\mathrm{S} 1$ for detailed parameter). There are two different kinds of $\mathrm{Pb}$ atom in the asymmetric unit. Each $\mathrm{Pb}$ atom forms a distorted octahedron with five oxygen atoms coordinating from five methyl sulphonate groups and the sixth being water oxygen. Methyl sulphonate group acts as
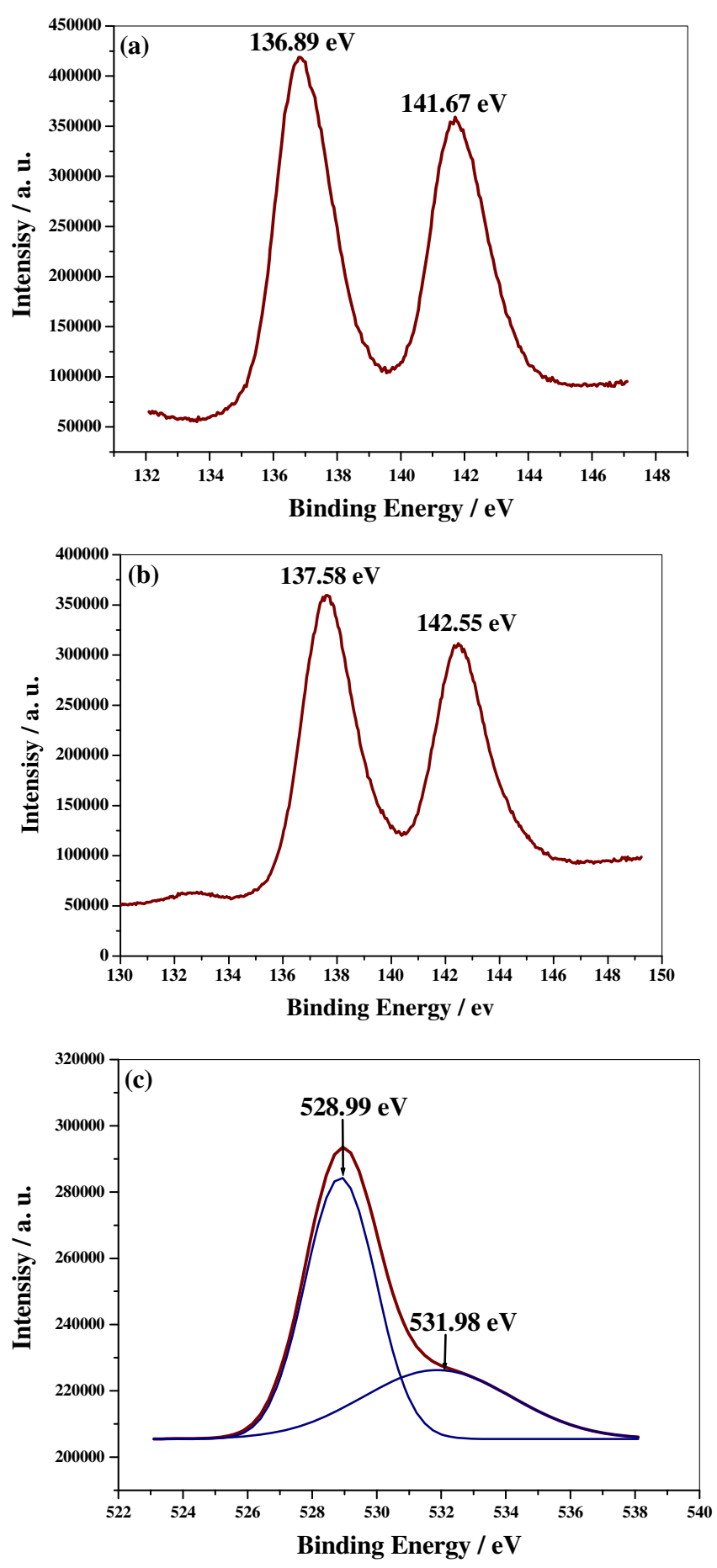

Figure 5. X-ray photoelectron spectra for (a) $\mathrm{Pb}(4 f)$ level of electrodeposited lead, (b) $\mathrm{Pb}(4 f)$ level of electrodeposited lead dioxide and (c) oxygen $(1 s)$ level of lead dioxide. 

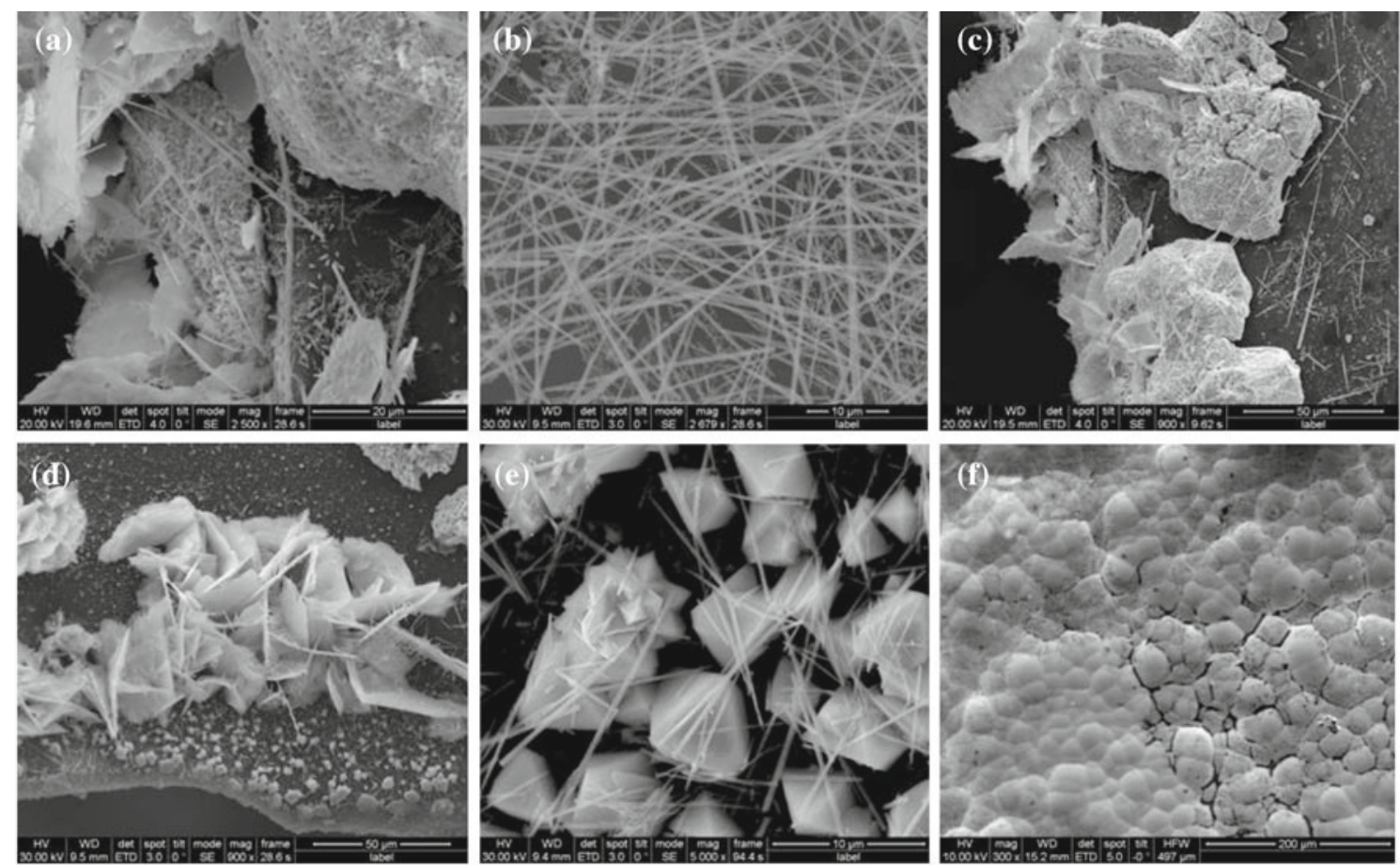

Figure 6. SEM images for inhomogeneous deposition of lead at different parts of negative current collector (a-e) and layer of $\mathrm{PbO}_{2}$ on positive current collector $(\mathbf{f})$.

a bridging ligand through oxygen coordination between the $\mathrm{Pb}$ atom resulting in infinite chains along crystallographic $b$ direction. Further these chains are inter connected via hydrogen bond along $c$ direction. Figure 3 represents packing diagram depicting the nature of coordination in each unit cell and the extended network as viewed down the $b$-axis.

To ensure phase purity of the synthesized compound, powder XRD pattern of lead (II) methanesulfonate was fitted using the above cell parameters (supplementary information, figure S4). The profile fitting ensures high purity of the compound. It is noteworthy that even after establishing structure of the material using single crystal diffraction technique, it is required that the phase purity is established based on powder diffraction particularly in case of materials for energy storage.

\subsection{Characterization of negative active material}

The electrodeposited negative active material was characterized by X-ray diffraction analysis, XPS study and SEM images. X-ray diffraction pattern for electrodeposited negative active material is shown in figure 4(a). The diffraction pattern is devoid of any peaks due to graphite substrate and it is clear that the pattern is for the deposited pure lead $(\mathrm{Pb})$ in cubic phase. XRD pattern for pristine graphite substrate is provided under supplementary information in figure S5. $\mathrm{Pb}(4 f)$ XPS spectrum for electrodeposited lead is shown in figure 5(a). The binding energy values of $4 f_{7 / 2}$ and $4 f_{5 / 2}$ are reflected at $136.89 \mathrm{eV}$ and $141.67 \mathrm{eV}$, respectively. SEM

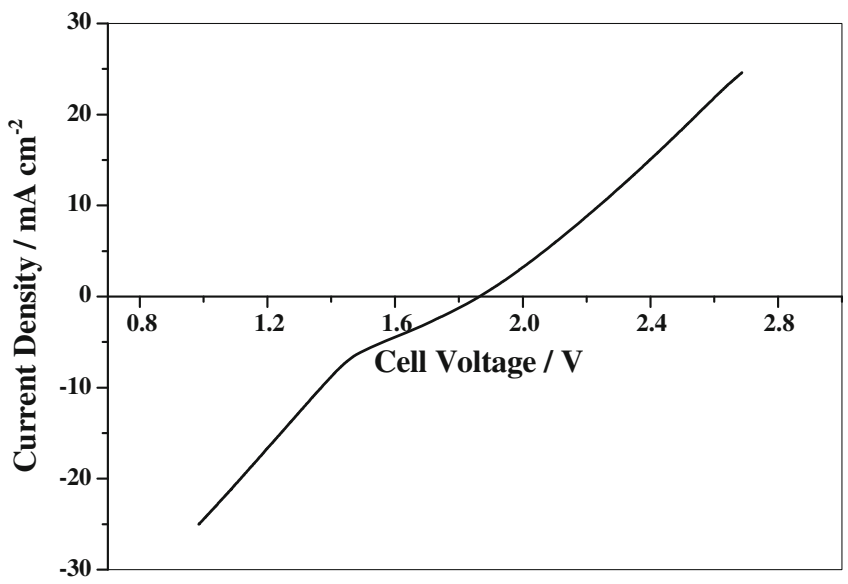

Figure 7. Current density vs cell voltage characteristic of solublelead redox flow battery.

images for electrodeposited $\mathrm{Pb}$ are shown in figures 6(a)(e). Electrodeposition of $\mathrm{Pb}$ is uneven and different parts of the electrode contain $\mathrm{Pb}$ particles with varying morphologies, viz. as porous agglomerate, fibre, petal, pyramidal, etc. There is substantial amount of dendritic $\mathrm{Pb}$ seen onto the current collector.

\subsection{Characterization of positive active material}

The electrodeposited positive active material was characterized by X-ray diffraction analysis, XPS study and SEM images in a similar fashion. The X-ray diffraction pattern 
for electrodeposited positive active material is shown in figure 4(b), which also is devoid of graphite substrate peaks. XRD pattern comprises of a few broad peaks due to $\beta$ $\mathrm{PbO}_{2}$ phase (tetragonal). In this pattern, few peaks are suppressed probably due to preferred orientation of the crystallographic planes. Broadening of XRD peaks is responsible due to the particle size in nano scale. The $\beta$-phase of lead dioxide is electrochemically active for the operation of leadacid battery (Monahov et al 2003; Pavlov et al 2004). An XPS spectrum of $\mathrm{Pb}(4 f)$ level for electrodeposited lead dioxide is shown in figure 5(b). In the spectrum, the binding energy values of $4 f_{7 / 2}$ and $4 f_{5 / 2}$ are reflected at $137.58 \mathrm{eV}$ and $142.55 \mathrm{eV}$, respectively; these values are slightly higher than lead metal. Figure 5(c) shows spectrum of oxygen $(1 s)$ level in lead dioxide with its characteristic doublets due to the double valence fluctuation of oxygen between $\mathrm{O}^{2-}$ and $\mathrm{O}_{2}^{2-}$ species (Ganguly and Hegde 1988). The corresponding peaks are seen at $528.99 \mathrm{eV}$ and $531.98 \mathrm{eV}$ with relative intensities of about $2: 1$, respectively.

A SEM image of the electrodeposited $\mathrm{PbO}_{2}$ layer is shown in figure 6(f). The deposition is smooth like sand dunes onto the surface of graphite current collector. Particle size of $\mathrm{PbO}_{2}$ is nearly $10-15 \mathrm{~nm}$ as obtained from the high resolution SEM images (see supplementary information in figure S6).

\subsection{Cell characterization by current density-cell voltage relationship}

Figure 7 shows typical current density-cell voltage relationship for the lead-acid flow battery. The characteristic data were recorded after $1 \mathrm{~h}$ of charging at $20 \mathrm{~mA} \mathrm{~cm}^{-2}$ current density. The current density vs cell voltage data are recorded from $25 \mathrm{~mA} \mathrm{~cm}^{-2}$ to $-25 \mathrm{~mA} \mathrm{~cm} \mathrm{~cm}^{-2}$ current at a scan rate of $0.5 \mathrm{~mA} \mathrm{~cm}^{-2} \mathrm{~s}^{-1}$. In the charging region, the cell voltage slowly increases with current density indicating the nucleation process of $\mathrm{Pb}$ and $\mathrm{PbO}_{2}$ onto the current collector. In this region, significant amount of overpotential is observed. The open circuit voltage of the cell is $1.86 \mathrm{~V}$ at zero current density. It is noteworthy that this value is slightly higher than the theoretical value because the experimental conditions differ in concentration and temperature. During discharge, the cell voltage suddenly decreases at about $1.46 \mathrm{~V}$ and thereafter, declines slowly with increase in current density (Pletcher and Wills 2004). The current density vs cell voltage data reflect on the kinetics of the electrode reactions and mass-transport limitation brought about by $\mathrm{Pb}^{2+}$ ions; the latter being responsible for the over-potential during cell charging.

\subsection{Constant current charge-discharge characteristics of soluble-lead redox flow battery}

Constant current $\left(20 \mathrm{~mA} \mathrm{~cm}^{-2}\right)$ charge-discharge characteristic data were recorded and voltage variations for positive and negative plate were recorded concomitantly against MMS reference electrode $(0.665 \mathrm{~V}$ vs SHE) as shown in figure 8 . In this plot, for the sake of convenience, individual plate potentials are reported with respect to SHE. The charge and discharge voltages for the cell are found to be $\sim 2.27 \mathrm{~V}$ and $\sim 1.36 \mathrm{~V}$, respectively. The cell capacity and faradaic efficiency obtained from the charging current $\left(20 \mathrm{~mA} \mathrm{~cm}^{-2}\right)$ and charging time $(1 \mathrm{~h})$ are $114 \mathrm{mAh} \mathrm{g}^{-1}$ of total active materials (both positive and negative) and 95\%, respectively. The charging voltages for positive and negative plates are found to be $\sim 2.00 \mathrm{~V}$ and $\sim-0.25 \mathrm{~V}$ vs SHE, respectively. Similarly, discharge voltage for the plates are $\sim 1.33 \mathrm{~V}$ and $\sim-0.06 \mathrm{~V}$ vs SHE, respectively. We had observed little graphitic corrosion on the positive plate during cell charging.

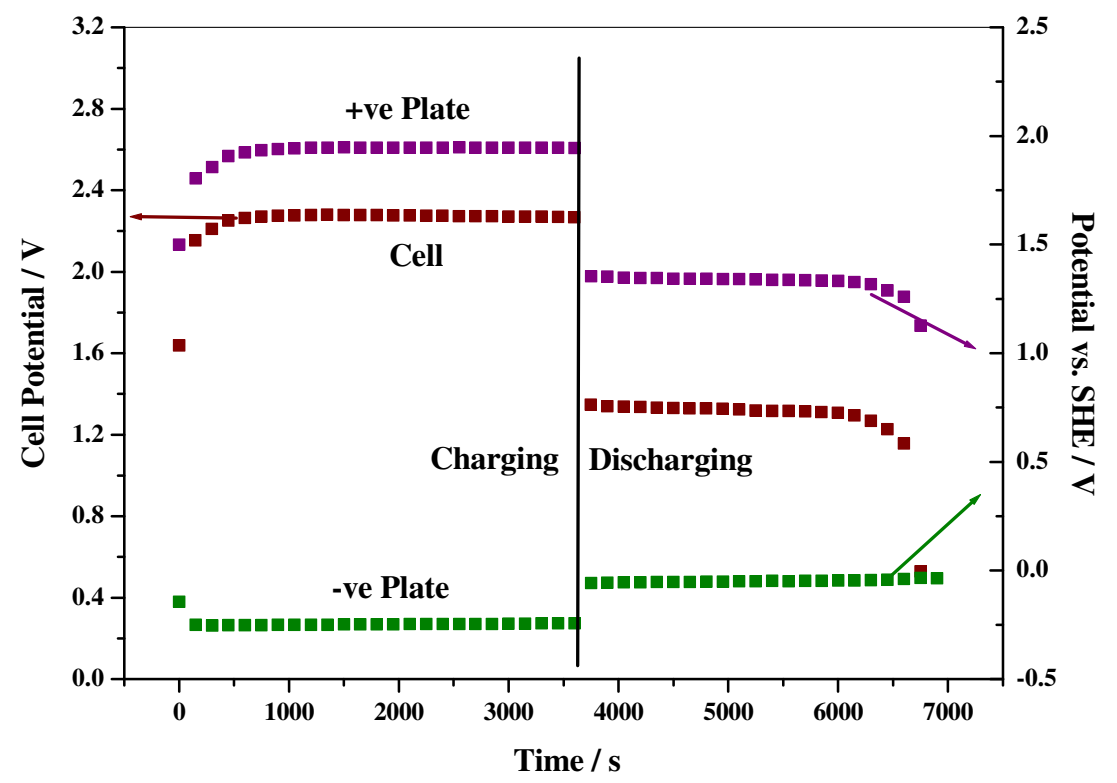

Figure 8. Constant-current charge-discharge characteristics for soluble-lead redox flow battery. 

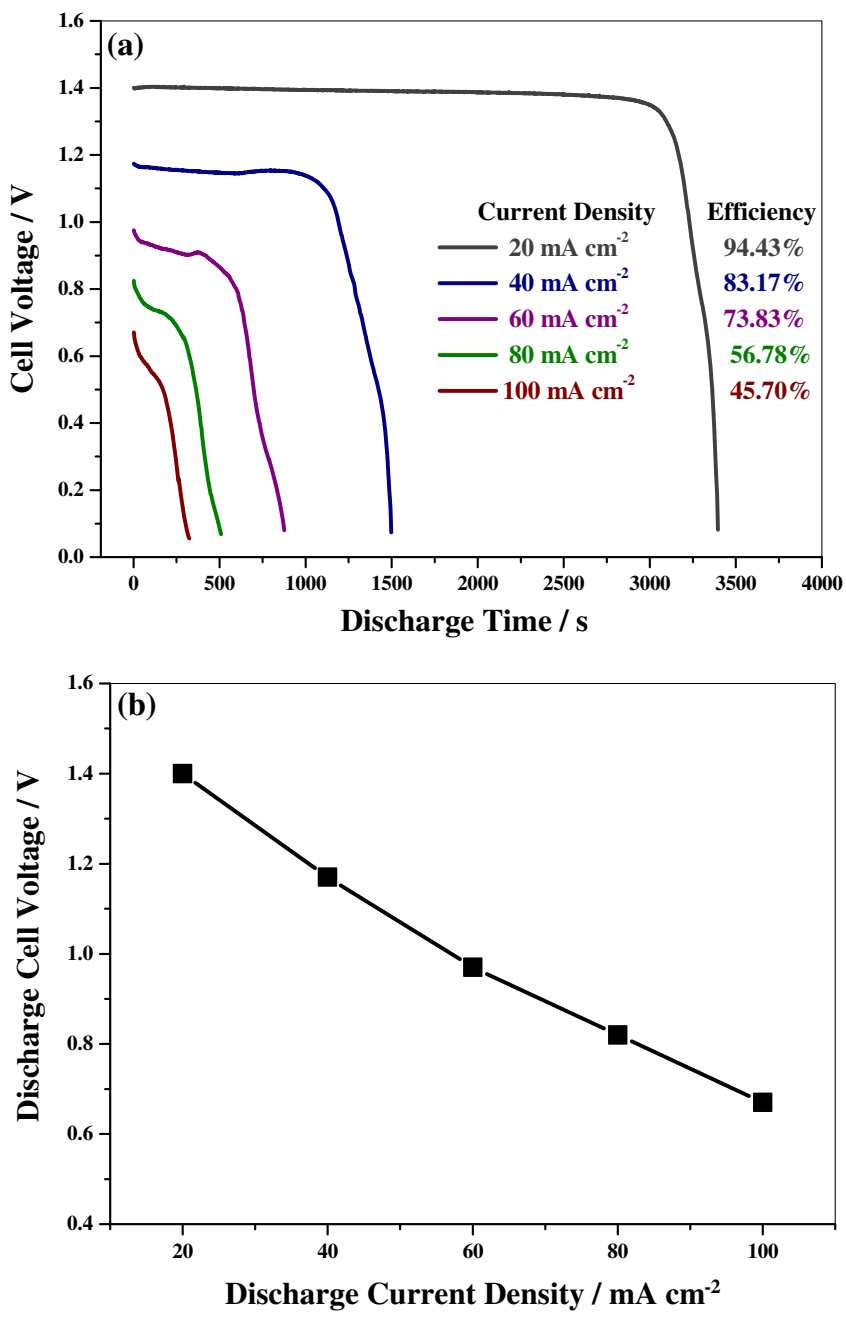

Figure 9. (a) Cell voltage vs discharge time plots at varying discharge current densities. Inset shows faradaic efficiency at different current densities. (b) Relationship between discharge current density and cell voltage.

\subsection{Influence of discharge current density on discharge voltage}

The flow cell was charged at $20 \mathrm{~mA} \mathrm{~cm}{ }^{-2}$ for $1 \mathrm{~h}$ in each case and then discharged at different current densities up to $0 \mathrm{~V}$; the discharge profiles are shown in figure 9(a). It is well known that with increasing current density, the discharge voltage decreases due to higher ohmic-drop. The current density vs discharge voltage plot is shown in figure 9(b). Not only the discharge voltage but also the cell efficiency decreases with increasing current density. This is due to the less utilization of active materials at higher current density.

\subsection{Cycle-life test for soluble-lead redox flow battery}

Cycle-life test is a crucial part for the performance of any energy storage device. In the study, the cell was charged at $20 \mathrm{~mA} \mathrm{~cm}^{-2}$ current density for $10 \mathrm{~min}$ and discharged at the same current density up to $1.2 \mathrm{~V}$. In between its charge and discharge, the cell was kept under open circuit for $1 \mathrm{~min}$. The cycle-life data are shown in figures 10(a)-(b). The chargedischarge profiles during cycling are given under supplementary information in figure S7. After 50 cycles, the capacity degrades, as shown in figure 10(a), due to the depletion of active materials, viz. $\mathrm{Pb}$, from the surface of current collectors. Owing to the irregular deposition and dendritic growth, $\mathrm{Pb}$ particles are not properly sustained onto the current collector during cycling. To circumvent this problem, $1 \mathrm{~g}$ litre $^{-1}$ of lignosulfonic acid sodium salt was added to electrolyte solution as an additive (Hazza et al 2005). The fine additive particles act as a seed during the nucleation process of $\mathrm{Pb}$ particles. Due to this, $\mathrm{Pb}$ deposition becomes homogeneous and smoother and aforesaid problem

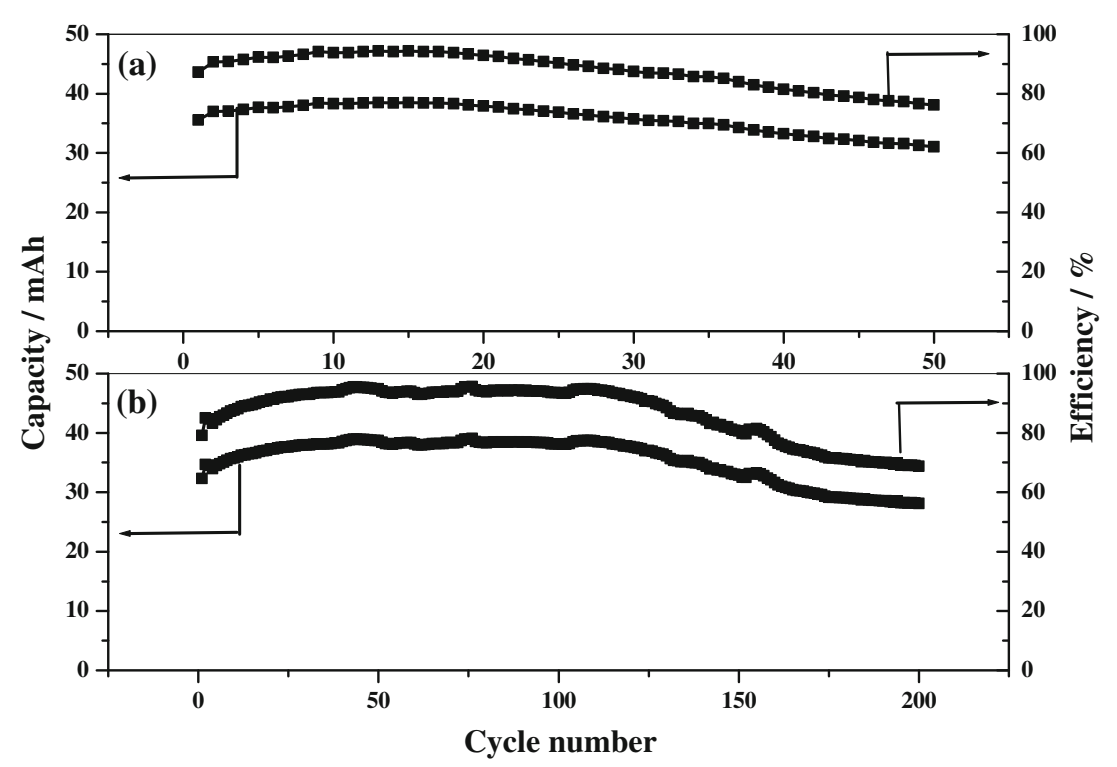

Figure 10. Cycle-life data (capacity and efficiency of cell vs cycle number) for soluble-lead redox flow battery: (a) without additive and (b) with additive. 

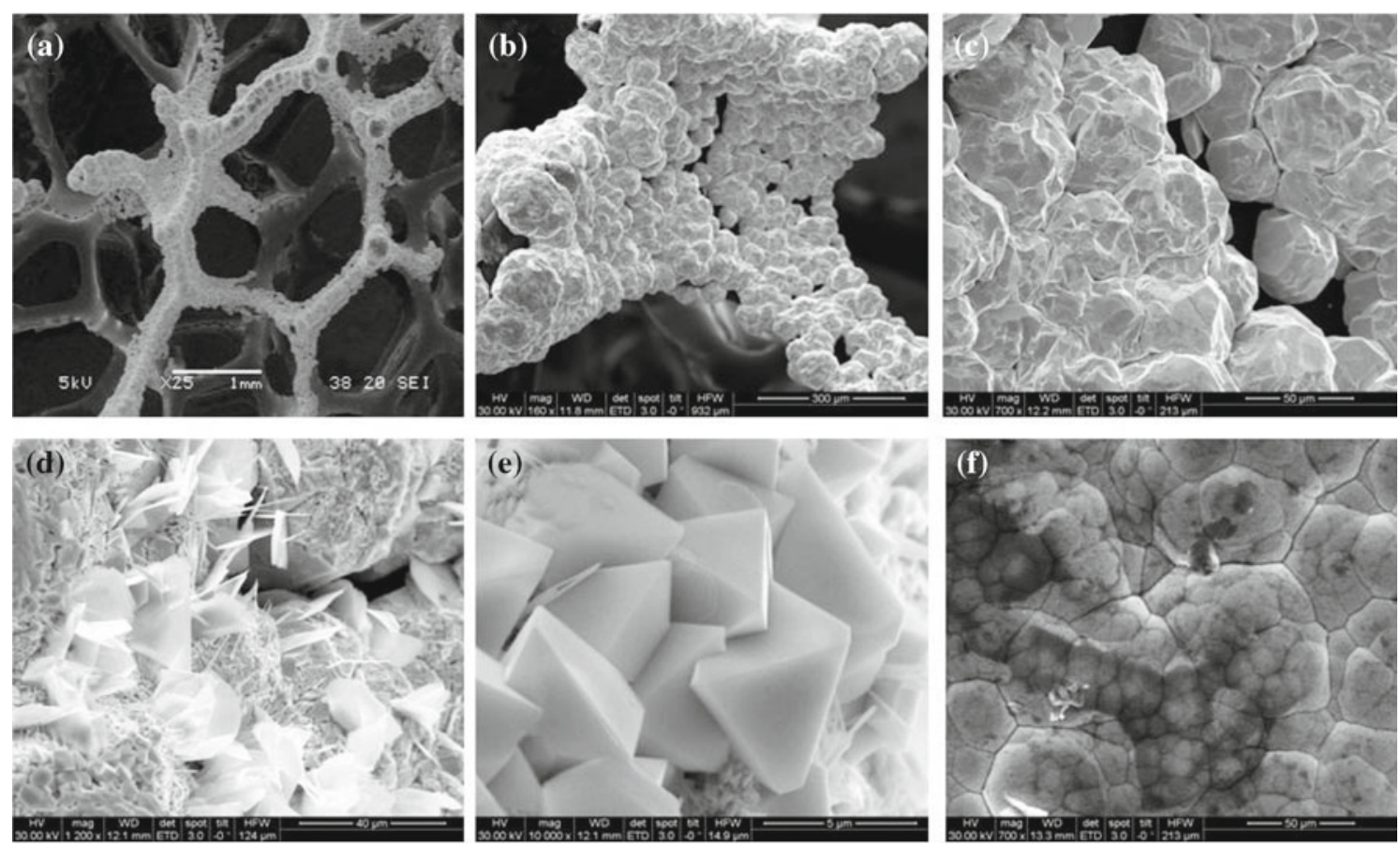

Figure 11. SEM images for homogeneous deposition of lead with increasing magnification (a-e) and layer of $\mathrm{PbO}_{2}$ on positive current collector (f).

is mitigated. The smooth $\mathrm{Pb}$ deposition images are shown in figures 11(a)-(e) with increasing magnification. We have also not observed much effect on positive plate due to the additive. In figure 11(f), from the SEM image, it is confirmed that there is no difference in $\mathrm{PbO}_{2}$ deposition with and without additive. By adding the lignosulfonic acid sodium salt to the electrolyte solution, the cycle-life increases substantially up to 200 cycles as shown in figure 10 (b).

\section{Conclusions}

An efficient soluble-lead redox flow battery was reported using corrugated graphite and reticulated vitreous carbon (RVC) as positive and negative current collectors. Electrodeposited materials onto the current collectors were characterized and cells were electrochemically tested. A capacity value of $114 \mathrm{mAh} \mathrm{g}^{-1}$ of total active materials (both positive and negative) with $95 \%$ faradaic efficiency at $20 \mathrm{~mA} \mathrm{~cm}^{-2}$ charge and discharge had been observed. 200 full chargedischarge cycles were completed successfully with nominal loss of capacity and efficiency by using sodium salt of lignosulfonic acid as an additive.

\section{Acknowledgements}

Financial support from the Department of Science \& Technology, Government of India, and Indian Institute of Science, Bangalore, under the Energy Storage Systems Initiative is gratefully acknowledged. A B thanks the Council of
Scientific and Industrial Research (CSIR), New Delhi, for a Senior Research Fellowship.

\section{Electronic supplementary material}

Supplementary material pertaining to this article is available on the Bulletin of Materials Science website (www.ias.ac.in/matersci).

\section{References}

Adam Z W and Meyers J P 2011 J. Appl. Electrochem. 411135

Agilent CrysAlis PRO and CrysAlis RED 2012 Agilent Technologies, Yarnton, England

Brandenburg K 1999 DIAMOND crystal, Impact GbR, Bonn, Germany

Farrugia L 1999 J. Appl. Crystallogr. 32837

Ganguly P and Hegde M S 1988 Phys. Rev. B37 5109

Hazza A, Pletcher D and Wills R 2004 Phys. Chem. Chem. Phys. 61773

Hazza A, Pletcher D and Wills R 2005 J. Power Sources 149103

Monahov B, Pavlov D, Kirchev A and Vasilev S 2003 J. Power Sources 113281

Pavlov D, Kirchev A, Stoycheva M and Monahov B 2004 J. Power Sources 137288

Petricek V, Dusek M and Palatinus L 2007 Jana2000

Peng H Y, Chen H Y, Li W S, Hu S J, Li H, Nan J M and Xu Z H 2007 J. Power Sources 168105

Pletcher D and Wills R 2004 Phys. Chem. Chem. Phys. 61779

Pletcher D and Wills R 2005 J. Power Sources 14996

Pletcher D, Zhou H, Kear G, Low C T J, Walas F C and Wills R G A 2008 J. Power Sources 180 621, 630

Sheldrick G M 2008 Acta Crystallogr. A64 112

Wills R G A, Collins J, Campbell D S, Low C T J, Pletcher D and Walsh F C 2010 J. Appl. Electrochem. 40955 